\title{
Thoracic perfusion of recombinant human endostatin (Endostar) combined with chemotherapeutic agents versus chemotherapeutic agents alone for treating malignant pleural effusions: a systematic evaluation and meta-analysis
}

\author{
Rong Biaoxue ${ }^{1 *}$, Cai Xiguang ${ }^{2}$, Liu Hua ${ }^{2}$, Gao Wenlong ${ }^{3}$ and Yang Shuanying ${ }^{4}$
}

\begin{abstract}
Background: Endostar is a new endogenous angiogenic inhibitor with implicated anti-tumor activity. This study was to investigate whether thoracic perfusion of Endostar could be used to control malignant pleural effusions (MPE).

Methods: We searched the databases of MEDLINE, Web of Science, EMBASE, Goggle, Cochrance Library and CNKI to select the studies regarding the efficacy of Endostar to treat MPE. A total of 13 randomised controlled trials (RCTs) with 1066 patients were included.

Results: The overall response rate $(\mathrm{ORR})(P<0.001$; odds ratio $=3.58)$ and disease control rate $(\mathrm{DCR})(P<0.001$; odds ratio $=2.97$ ) of Endostar combined with chemotherapeutic agents were significantly higher than those of chemotherapeutic agents alone. In addition, Endostar combined treatment remarkably promoted quality of life $(\mathrm{QOL})$ of patients $(P<0.001$; odds ratio $=3.04)$ compared with that of chemotherapeutic agents alone. Moreover, Endostar combined treatment did not have an impact on the incidence of adverse reactions (AEs) $(P<0.05)$.

Conclusions: The efficacy of Endostar combined chemotherapeutic agents was superior to chemotherapeutic agents alone through thoracic perfusion in treating MPE, which indicated that Endostar could be an effective agent for controlling MPE.
\end{abstract}

Keywords: Endostar, Malignant pleural effusions, MPE, Meta-analysis, Efficacy, Safety

\section{Background}

In China, lung cancer has been becoming a major cause of death in malignant tumors due to increasingly air pollution and deterioration of the natural environment. In 2015 in China, There is dreadful fact that 733,000 lung cancer cases were diagnosed and 610,000 patients will die from this disease [1]. In clinic, most of lung cancer patients always are accompanied with the event of

\footnotetext{
* Correspondence: research568rbx@yeah.net

'Department of Respiratory Medicine, First Affiliated Hospital, Xi'an Medical

University, 48 Fenghao West Road, Xi'an 710077, China

Full list of author information is available at the end of the article
}

malignant pleural effusions (MPE), which leads to a lower quality of life and even reduced the life expectancy. Thus, doctors often pay more attention to the treating of MPE and the prolongation of survival [2]. Traditional treatments of MPE include drainage of pleural effusion, pleural adhesions and pharmacotherapy and so on. In addition, thoracic perfusion of chemotherapeutic agents has been suggested to be used in controlling of the effusion. The main opinion is that the intrapleural levels of a chemotherapy agent administered into the pleural space can be significantly higher than the systemic levels [3]. However, most of lung cancer 
cases are often resistant to standard chemotherapy agent, or eventually become chemoresistant. Therefore, the fact is many chemotherapeutic agents are not as effective as we expected in treating MPE via thoracic perfusion [4]. Today, novel molecular targeted drugs that have been studied to improve the cure and control rate of the disease. Because of strong antineoplastic activity and low toxicity, these products have been used as alternative treatments for the control of MPE [5].

Endostatin is a naturally-occurring, 20-kDa C-terminal fragment derived from type XVIII collagen, which was first reported by Folkman. Endostatin has been reported to inhibit angiogenesis in a wide range of tumors, and may interfere with the pro-angiogenic effects of growth factors. Capillary endothelial cells are the targets of endostatin, endostatin blocks endothelial cell proliferation and formation of new blood vessels, and affects the progress and metastasis of malignant tumors [6]. A new recombinant human endostatin (code number: $\mathrm{YH}-16$ ), Endostar, is developed by Simcere-Medgenn Bioengineering Co. Ltd, Nanjing and Yantai, China, and is different from the original endostatin studied by O'Reilly [6, 7], which was approved by the China State Food and Drug Administration (SFDA) for the treatment of non- small cell lung cancer as the first therapy in 2005 [8]. Endostar has a structural difference compared with endostatin reported in previous literature, which purified in Escherichia coli with an additional nine-amino acid sequence (MGGSHHHHH) $[9,10]$. Some studies suggested that the antiangiogenic biological function has been promoted because of such a structural changes on this drug in treating lung cancer $[8,11,12]$.

Recent years, some studies have specially investigated the clinical effect and safety of Endostar combined with chemotherapeutic agents versus chemotherapeutic agents alone in treating MPE via thoracic perfusion. Here, we performed a systematic literature review to assess the clinical benefit of Endostar combined therapy in treating MPE.

\section{Methods}

\section{Identification of literature}

We searched and identified relevant randomized controlled trials (RCTs) from the databases of MEDLINE/ PubMed, EMBASE, Cochrance Library, SCI, and CNKI database (from January 2005 to April 2016). We adopted various MeSH terms and key words that related to MPE and Endostar as follows: "malignant pleural effusion," "MPE," "rh-endostatin," "endostatin," "chemotherapy," "Endostar," and "recombinant human endostatin injection." In addition, if we found useful information that was intimately associated with Endostar in the reference lists of those studies, we should further look for additional studies and identified them.

\section{Collection of study variables}

The data that we extracted included: (1) the number of patients of each RCT, (2) publication date of literature, (3) the clinical characteristics of data, (4) the ways of clinical intervention, (5) overall response (ORR) and disease control rate (DCR) and (6) quality of life (QOL) and adverse effects (AEs).

\section{Criteria that studies were included and excluded}

Inclusion criteria: (1) studies must be designed to compare Endostar plus chemotherapeutic agents to chemotherapeutic agents alone; (2) patients must be given drugs through thoracic perfusion; (3) patients must be diagnosed with MPE; (4) outcome measures must be reported; and (6) the total cases of patients must be greater than or equal to (but not less than) 50. Exclusion criteria: (1) studying on animals not human; (2) patients were given excessive other adjutant drugs; (3) studies were sponsored by pharmaceutical manufacturers; and (4) study was short of efficient control group.

\section{Supervision of the implementation process}

Trial design: RCTs of Endostar combined with chemotherapeutic agents versus chemotherapeutic agents alone through thoracic perfusion for treating MPE. The ways of interventions: the dosage was defined according to the statement of manufacturers and frequency of administration at least 2 times; Evaluation indicators of therapeutic efficacy: ORR, DCR, QOL, and AEs.

\section{Quality assessment of included RCTs}

We utilized the evaluation criteria shaped by Cochrane Handbook (Version 5.0.1) to assess the included trials, which included: (1) methods to random group of patients; (2) how to perform an adequate setting blinding; (3) how to perform an adequate allocation and conceal the sequence; and (4) a description of intention to treat. Eventually, the quality of trials was divided into three levels: low risk of bias, unclear risk of bias, and high risk of bias $[13,14]$.

\section{Statistical methods and analysis}

After sufficient data were collected and identified, the process of meta-analysis was implemented. The odds ratio (OR) with $95 \%$ confidence intervals (CI) were major statistical data that were applied to explore the difference of efficacy. The overall effect was calculated by $\mathrm{Z}$-scores and $P$-values $<0.05$ were considered to be statistically significant. The identification of homogeneity was studies was calculated by the $\chi^{2}$ statistic and was quantified with the $\mathrm{I}^{2}$ statistic. In our study, we adopted fixed effects model preferential to perform meta-analysis. We also used meta-regression to evaluate whether the results were different between two groups. 
In order to assess the bias of literature, we omitted each study from the estimated pool to analyze the influence of each study to overall effect. In addition, funnel plots, Egger's test, and Begg's test were performed to assess publication bias. We used SPSS (SPSS Institute, version 19.0, Chicago, USA) and Stata version 15.0 (Stata Corporation, TX, USA) to implement the statistical analysis and used a significance level of $P<0.05$.

\section{Results}

\section{Study selection process}

Originally, 122 potentially relevant studies were identified. Of them, 66 studies were removed because they were not original literature such as review, abstract and meeting records. Remaining 56 studies were identified as requiring RCTs, but 31 studies were excluded subsequently because of the following reasons: did not describe a clear control; did not have usable end points; duplicate of another study; non-human studies; low quality of statistics; and too small sample size. Of the remaining 25 trials, 12 were excluded further because complicated combination therapy and low design quality. Finally, 13 [15-27] studies published between 2010 and 2015 were included (Fig. 1). The eligible studies contained a total of 1066 patients with the sizes of distributing from 56 [18] to 120 [20] patients. The cause of MPE mainly included lung cancer (918 cases), breast cancer (78 cases) and digestive tract tumors (56 cases). A meta-analysis database was established according to the extracted data, which was listed in Tables 1 and 2 .

\section{Quality of study design}

The design of 8 studies were that Endostar combined with cisplatin versus cisplatin alone through thoracic perfusion for treating MPE $[15,16,18,20,21,23,24,27], 2$ studies were Endostar combined with bleomycin versus bleomycin alone [17, 26], 2 studies Endostar combined with nedaplatin versus nedaplatin alone $[19,25]$ and one Endostar combined with lobaplatin versus lobaplatin alone [22]. The dosage of Endostar via thoracic perfusion and follow-up times for efficacy evaluation had a good consistency, which was shown in Table 2. Generally, the dosage of Endostar was administered at the range of 30-90 mg per one time and frequency of administration was two times at least, which were dissolved in physiological saline, and given by thoracic perfusion after drainage of pleural effusions.

\section{Quality of study characteristics}

Two investigators independently reviewed and determined the quality of each study. The discrepancies were resolved by consensus with the third expert. The evaluation was performed according to the evaluation criteria established by Cochrane Handbook (Version 5.0.1) [28]. As shown in Table 3, the results showed that 4 of the 13 studies (30.7\%) belonged to the low risk of bias [17, 20, $24,27]$, and the rest $[1,4,5,8-10,15,16,18,19,21-23$, $25,26,29$ ] were inclined to indicate an unclear risk of bias (69\%) (Table 3).

\section{Comparison of ORR}

We identified 13 RCTS [15-27] pertaining to ORR comparison. The odds ratio of fixed-effects was 3.58 (95 \% CI 2.73 to 4.69; $Z=9.24, p<0.001$; Fig. 2), which indicated that the ORR of Endostar combined treatment was significantly higher than that of chemotherapeutic agents alone. Among these 13 studies, we did not observe the evidence of heterogeneity

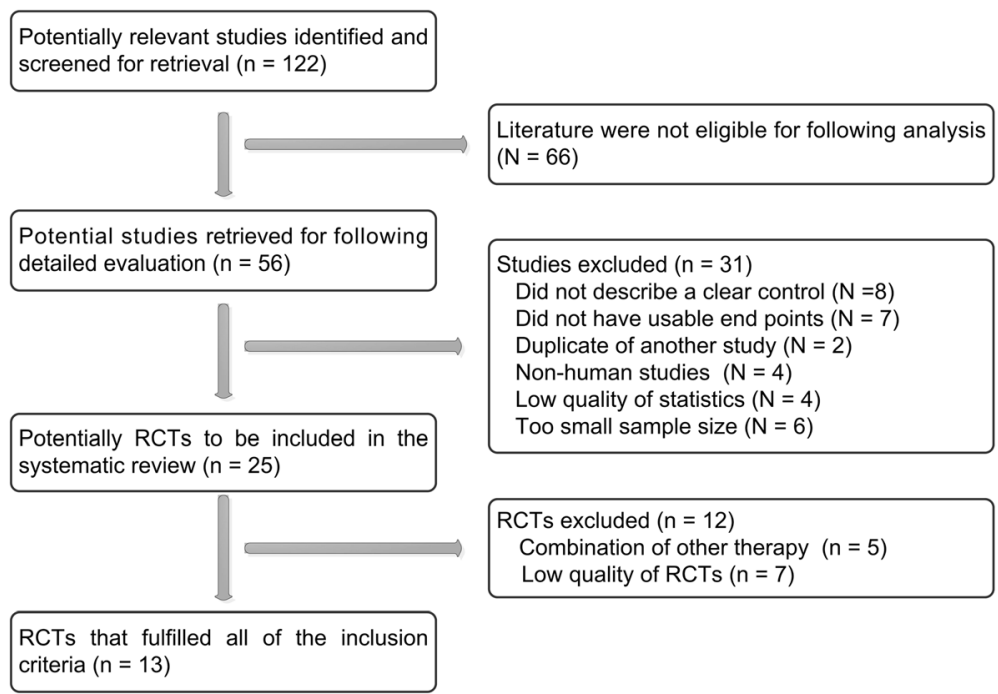

Fig. 1 Flow chart of literature search. RCTs, randomized controlled trials 
Table 1 Data analysis of included studies

\begin{tabular}{|c|c|c|c|c|c|c|c|c|c|c|c|}
\hline \multirow[t]{2}{*}{ Study } & \multirow[t]{2}{*}{$N$} & \multirow[t]{2}{*}{ Male } & \multirow[t]{2}{*}{ Female } & \multirow[t]{2}{*}{ Age (average) } & \multicolumn{4}{|c|}{ Sources of tumor (N) } & \multirow[t]{2}{*}{ Volume of MPE (N) } & \multirow[t]{2}{*}{ Quality of Life } & \multirow[t]{2}{*}{ End point } \\
\hline & & & & & Lung/pleura & Breast & Digestive tract & Others & & & \\
\hline Liu W 2010 [15] & 96 & 51 & 45 & $40-70$ & 96 & - & - & - & Unavailable & KPS & $\mathrm{RR}, \mathrm{DCR}, \mathrm{SI}, \mathrm{AES}$ \\
\hline Mao L 2011 [16] & 90 & 45 & 45 & $27-70$ & 81 & 5 & 2 & 2 & $>1000 \mathrm{ml}$ & KPS & RR, DCR, SI, AEs \\
\hline Li G 2011 [17] & 60 & 30 & 30 & $41-76$ & 25 & 20 & 15 & - & $\begin{array}{l}\text { Large (37) } \\
\text { Moderate (23) }\end{array}$ & KPS & RR, DCR, SI, AEs \\
\hline Ma E 2012 [18] & 56 & 32 & 24 & $35-67$ & 56 & - & - & - & $>1000 \mathrm{ml}$ & Unavailable & RR, DCR, SI, AEs \\
\hline Yao Q 2012 [19] & 60 & 42 & 18 & $35-78$ & 28 & 16 & 4 & 12 & $>1000 \mathrm{ml}$ & KPS & RR, DCR, SI, AEs \\
\hline Zheng Q 2013 [20] & 120 & 73 & 47 & $32-75$ & 78 & 25 & 17 & - & $>1000 \mathrm{ml}$ & KPS & RR, DCR, SI, AEs \\
\hline Kang Y 2013 [21] & 90 & 53 & 37 & $18-72$ & 90 & - & - & - & $>1000 \mathrm{ml}$ & KPS & $\mathrm{RR}, \mathrm{DCR}, \mathrm{SI}, \mathrm{AES}$ \\
\hline Wen J 2014 [22] & 60 & 34 & 26 & $35-65(50.5)$ & 45 & 9 & 6 & - & $\begin{array}{l}\text { Large (13) } \\
\text { Moderate (29) } \\
\text { Small (18) }\end{array}$ & KPS & RR, DCR, SI, AEs \\
\hline Yue G 2014 [23] & 86 & 48 & 42 & $38-69$ & 86 & - & - & - & Unavailable & KPS & RR, DCR, SI, AEs \\
\hline Tu J 2014 [24] & 90 & 41 & 49 & $45-70$ & 90 & - & - & - & Unavailable & KPS & RR, DCR, SI, AES \\
\hline Xu J 2014 [25] & 70 & 43 & 27 & $44-70$ & 70 & - & - & - & $>1000 \mathrm{ml}$ & KPS & RR, DCR, SI, AEs \\
\hline Wen X 2015 [26] & 104 & 69 & 35 & $39-76$ & 104 & - & - & - & Unavailable & KPS & RR, DCR, SI, AEs \\
\hline $\mathrm{Hu} \times 2015$ [27] & 84 & 62 & 22 & $18-70$ & 69 & 3 & 12 & - & $>1000 \mathrm{ml}$ & ECOG & RR, DCR, SI, AEs \\
\hline
\end{tabular}

$N$ number of patients, MPE malignant pleural effusion, KPS karnofsky physical status score, RR response rate, $D C R$ disease control rate, SI symptom improvement, $A E s$ adverse effects, ECOG Eastern Cooperative Oncology Group (performance status) 
Table 2 Assessment of administration of included studies

\begin{tabular}{|c|c|c|c|c|c|c|}
\hline \multirow[t]{2}{*}{ Study } & \multirow{2}{*}{$\begin{array}{l}\text { Trial } \\
\text { group }(M)\end{array}$} & \multirow{2}{*}{$\begin{array}{l}\text { Control } \\
\text { group }(N)\end{array}$} & \multicolumn{2}{|l|}{ Interventions } & \multirow{2}{*}{$\begin{array}{l}\text { Treatment } \\
\text { cycle }\end{array}$} & \multirow{2}{*}{$\begin{array}{l}\text { Termination of } \\
\text { treatment }\end{array}$} \\
\hline & & & $\begin{array}{l}\text { Endostar combined with } \\
\text { chemotherapeutic agents }\end{array}$ & $\begin{array}{l}\text { Chemotherapeutic agents } \\
\text { alone }\end{array}$ & & \\
\hline Liu W 2010 [15] & 32 & 32 & $\begin{array}{l}\text { Cisplatin } 40 \mathrm{mg} / \mathrm{m}^{2}, 1 / \text { week } \\
\text { Endostar } 30 \mathrm{mg}, 1 / \text { week }\end{array}$ & Cisplatin $40 \mathrm{mg} / \mathrm{m}^{2}, 1 / \mathrm{w}$ & 3 weeks & $\begin{array}{l}>3 \text { weeks, or pleural } \\
\text { effusion disappeared }\end{array}$ \\
\hline Mao L 2011 [16] & 45 & 45 & $\begin{array}{l}\text { Cisplatin } 40 \text { mg/m², 1/week } \\
\text { Endostar } 30 \text { mg, 2/week }\end{array}$ & Cisplatin $40 \mathrm{mg} / \mathrm{m}^{2}, 1 / 7 \mathrm{~d}$ & $\begin{array}{l}7 \mathrm{~d} / \text { cycle, } \\
2 \text { cycles }\end{array}$ & $\begin{array}{l}>4 \text { cycles, or pleural } \\
\text { effusion disappeared }\end{array}$ \\
\hline Li G 2011 [17] & 30 & 30 & $\begin{array}{l}\text { Bleomycin } 60 \text { mg, 1/week } \\
\text { Endostar } 30 \text { mg, 1/week }\end{array}$ & Bleomycin $60 \mathrm{mg}, 1 / \mathrm{w}$ & 3 weeks & $\begin{array}{l}>3 \text { weeks, or pleural } \\
\text { effusion disappeared }\end{array}$ \\
\hline Ma E 2012 [18] & 28 & 28 & $\begin{array}{l}\text { Cisplatin } 40 \mathrm{mg} / \mathrm{m}^{2}, 1 / \text { week } \\
\text { Endostar } 30 \mathrm{mg}, 1 / \text { week }\end{array}$ & Cisplatin $40 \mathrm{mg} / \mathrm{m}^{2}, 1 / \mathrm{w}$ & 4 weeks & $\begin{array}{l}>4 \text { weeks, or pleural } \\
\text { effusion disappeared }\end{array}$ \\
\hline Yao Q 2012 [19] & 30 & 30 & $\begin{array}{l}\text { Nedaplatin } 40 \text { mg, 1/week } \\
\text { Endostar } 45 \text { mg, 1/week }\end{array}$ & Nedaplatin 40 mg, 1/w & 4 weeks & $\begin{array}{l}>4 \text { weeks, or pleural } \\
\text { effusion disappeared }\end{array}$ \\
\hline Zheng Q 2013 [20] & 60 & 60 & $\begin{array}{l}\text { Cisplatin } 30-40 \mathrm{mg} \text {, d1-3 } \\
\text { Endostar } 90 \mathrm{mg}, \mathrm{d} 4\end{array}$ & Cisplatin $30-40 \mathrm{mg} \mathrm{d} 1-3$ & $\begin{array}{l}21 \mathrm{~d} / \text { cycle, } \\
1-4 \text { cycles }\end{array}$ & $\begin{array}{l}>4 \text { cycles, or pleural } \\
\text { effusion disappeared }\end{array}$ \\
\hline Kang Y 2013 [21] & 45 & 45 & $\begin{array}{l}\text { Cisplatin } 40 \text { mg, 2/week } \\
\text { Endostar } 30 \text { mg, 2/week }\end{array}$ & Cisplatin $40 \mathrm{mg}, 2 / \mathrm{w}$ & 3 weeks & $\begin{array}{l}>3 \text { weeks, or pleural } \\
\text { effusion disappeared }\end{array}$ \\
\hline Wen J 2014 [22] & 25 & 29 & $\begin{array}{l}\text { Lobaplatin } 30 \mathrm{mg} / \mathrm{m}^{2}, \mathrm{~d} 1 \\
\text { Endostar } 30 \mathrm{mg}, \mathrm{d} 1\end{array}$ & Lobaplatin 30 mg/m², d1 & 4 cycles & $\begin{array}{l}>4 \text { cycles, or pleural } \\
\text { effusion disappeared }\end{array}$ \\
\hline Yue G 2014 [23] & 43 & 43 & $\begin{array}{l}\text { Cisplatin } 60 \text { mg, 1/week } \\
\text { Endostar } 30 \text { mg, 2/week }\end{array}$ & Cisplatin $60 \mathrm{mg}, 1 / \mathrm{w}$ & 2-3 weeks & $\begin{array}{l}>4 \text { weeks, or pleural } \\
\text { effusion disappeared }\end{array}$ \\
\hline Tu J [24] & 45 & 45 & $\begin{array}{l}\text { Cisplatin } 40 \text { mg/m², 2/week } \\
\text { Endostar } 45 \mathrm{mg}, 2 / \text { week }\end{array}$ & Cisplatin $40 \mathrm{mg} / \mathrm{m}^{2}, 2 / \mathrm{w}$ & 3 weeks & $\begin{array}{l}>3 \text { weeks, or pleural } \\
\text { effusion disappeared }\end{array}$ \\
\hline Xu J 2014 [25] & 35 & 35 & $\begin{array}{l}\text { Nedaplatin } 60 \text { mg, 1/week } \\
\text { Endostar } 60 \text { mg, 1/week }\end{array}$ & Nedaplatin 60 mg, 1/w & 4 weeks & $\begin{array}{l}>4 \text { weeks, or pleural } \\
\text { effusion disappeared }\end{array}$ \\
\hline Wen X 2015 [26] & 68 & 36 & $\begin{array}{l}\text { Bleomycin } 45 \text { mg, w1 } \\
\text { Endostar } 45 \text { mg, w2 }\end{array}$ & Bleomycin 45 mg, 1/7d & $\begin{array}{l}7 \mathrm{~d} / \text { /cycle, } \\
2-4 \text { cycles }\end{array}$ & $\begin{array}{l}>2 \text { weeks, or pleural } \\
\text { effusion disappeared }\end{array}$ \\
\hline Hu X 2015 [27] & 43 & 41 & $\begin{array}{l}\text { Cisplatin } 40 \text { mg, 2/week } \\
\text { Endostar } 60 \text { mg, 2/week }\end{array}$ & Cisplatin 40 mg, 2/week & 2 weeks & $\begin{array}{l}>2 \text { weeks, or pleural } \\
\text { effusion disappeared }\end{array}$ \\
\hline
\end{tabular}

$N$ numbers of patients, $d$ day, $w$ week

(heterogeneity chi-squared $=8.23 ; \quad p=0.767$ ). Moreover, sensitivity analysis revealed the odds ratio and $95 \%$ CI did not change when we omitted anyone study, with an odds ratio pool changing between 2.08 to 6.82 .

\section{Comparison of DCR}

Eleven trials [15, 17-22, 24-27] compared the DCR. The odds ratio of the fixed effects model ranged from 0.96 to seven and did not imply the existence of heterogeneity (heterogeneity chi-squared $=6.15 ; \quad p=0.803$ ) . The pooled odds ratio was 2.97 (95\% CI 2.02 to 4.35; $\mathrm{Z}=5.57, p<0.001)$, which indicated that Endostar combined with chemotherapeutic agents promoted the DCR, compared with chemotherapeutic agents alone (Fig. 3).

\section{Comparison of QOL after treatment}

Twelve studies [15-24, 26, 27] investigated the changes of QOL after treatment. The Endostar combination arms had a higher symptom improvement rate than chemotherapeutic agents alone (odds ratio $=3.04,95 \%$ CI 2.28 to 4.04; test for overall effect: $\mathrm{Z}=7.64, p<0.001$ ) (Fig. 4).

\section{Adverse reactions comparison of two projects}

As shown in Table 4, nine studies compared the adverse effects, which presented five common AEs including myelotoxicity, gastrointestinal toxicity, liver and renal function injury, arrhythmia and fever. The meta-analysis showed that incidence of myelotoxicity [17, 19-25, 27] were similar in Endostar combined with chemotherapeutic agents and chemotherapeutic agents alone (odds ratio $=1.14,95 \%$ CI 0.83 to $1.58, p=0.423$ ) (Fig. 5a). The incidence of gastrointestinal toxicity in two projects $[17,19-25,27]$ did not have a significant difference (odds ratio $=1.25,95 \%$ CI 0.88 to $1.80, p=0.214$ ) (Fig. 5b). Five studies [17, 21, 24, 25, 27] compared liver and renal injury, six studies compared arrhythmia [17, $21,22,24,25,27]$, and four studies compared fever, all results suggested that the incidence rate of these AEs did not have differences between both of two projects $(p>0.05)$ (Fig. 6a, b and c).

\section{Assessment of publication bias and meta-regression analysis}

The shape of Begg's funnel plot seems to be symmetrical (Std. Dev. of Score $=16.39, \quad \mathrm{z}=0.37, \quad \operatorname{Pr}>\mathrm{z}=0.716$ ), 
Table 3 Design quality of included trials

\begin{tabular}{|c|c|c|c|c|c|c|c|c|c|}
\hline Studies & Region & Sequence generation & $\begin{array}{l}\text { Allocation } \\
\text { concealment }\end{array}$ & Blind & $\begin{array}{l}\text { Outcome } \\
\text { data }\end{array}$ & $\begin{array}{l}\text { Selective outcome } \\
\text { reporting }\end{array}$ & $\begin{array}{l}\text { Other sources } \\
\text { of bias }\end{array}$ & ITT & Risk of bias \\
\hline Liu W 2010 [15] & Single center & Random number table (SPSS) & Clear & Clear & Yes & No & Clear & No & Unclear risk of bias \\
\hline Mao L 2011 [16] & Single center & Random number table (SAS) & Unclear & Unclear & Yes & No & Clear & Yes & Unclear risk of bias \\
\hline Li G 2011 [17] & Single center & Random number table (SAS) & sufficient & Unclear & Yes & No & Clear & Yes & Low risk of bias \\
\hline Ma E 2012 [18] & Single center & Random number table (SPSS) & Unclear & Unclear & Yes & No & Clear & No & Unclear risk of bias \\
\hline Yao Q 2012 [19] & Single center & Random number table (SPSS) & Unclear & Unclear & Yes & No & Clear & No & Unclear risk of bias \\
\hline Zheng Q 2013 [20] & Single center & Random number table (SAS) & sufficient & Unclear & Yes & No & Clear & Yes & Low risk of bias \\
\hline Kang Y 2013 [21] & Single center & Random number table (SAS) & Unclear & Unclear & Yes & NO & Clear & Yes & Unclear risk of bias \\
\hline Wen J 2014 [22] & Single center & unclear & Unclear & Unclear & Yes & NO & Clear & Yes & Unclear risk of bias \\
\hline Yue G 2014 [23] & Single center & Random number table (SAS) & Unclear & Unclear & Yes & No & Clear & Yes & Unclear risk of bias \\
\hline Tu J 2014 [24] & Single center & Random number table (SPSS) & Insufficient & Unclear & Yes & No & Unclear & Yes & Low risk of bias \\
\hline Xu J 2014 [25] & Single center & Random number table (SPSS) & Unclear & Clear & Yes & No & Unclear & No & Unclear risk of bias \\
\hline Wen X 2015 [26] & Single center & Random number table (SPSS) & Unclear & Unclear & Yes & No & Clear & No & Unclear risk of bias \\
\hline $\mathrm{Hu} \times 2015$ [27] & Single center & unclear & Insufficient & Unclear & Yes & No & Clear & No & Low risk of bias \\
\hline
\end{tabular}




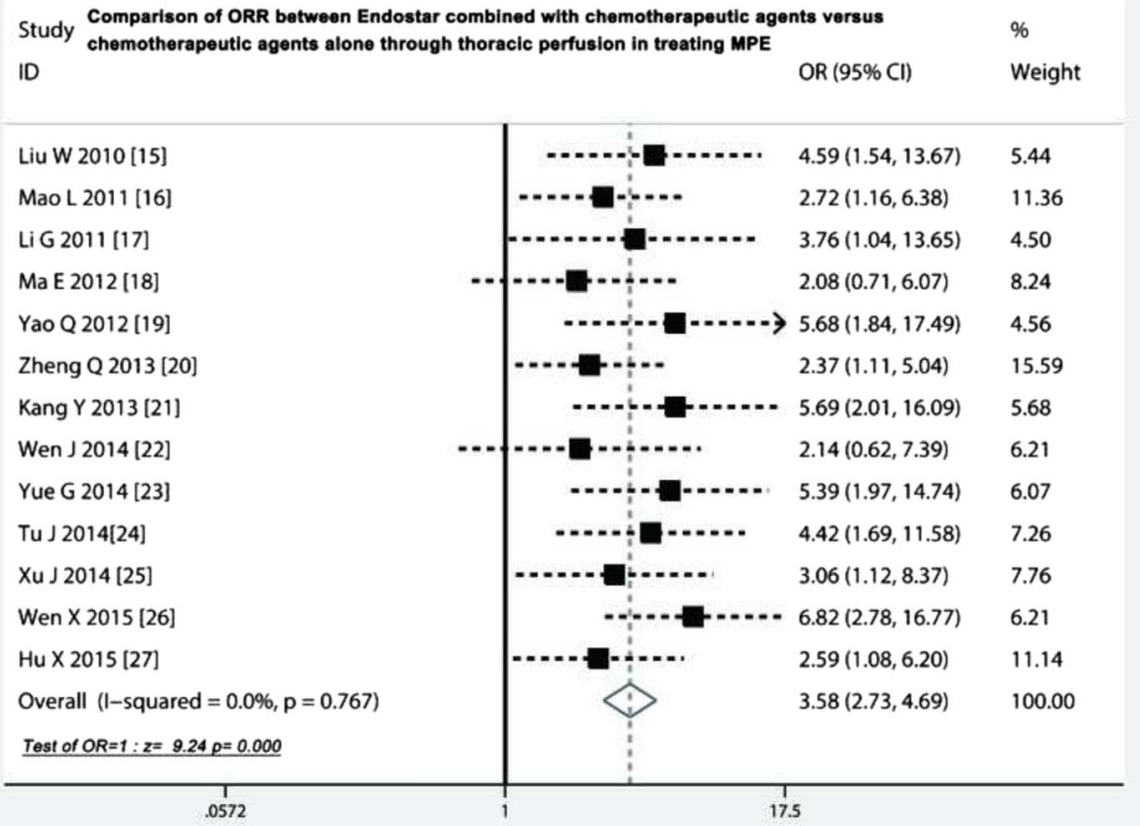

Fig. 2 Comparison of ORR between Endostar combined with chemotherapeutic agents versus chemotherapeutic agents alone through thoracic perfusion for treating MPE. ORR, overall response rate; OR, odds ratio; MPE, malignant pleural effusions

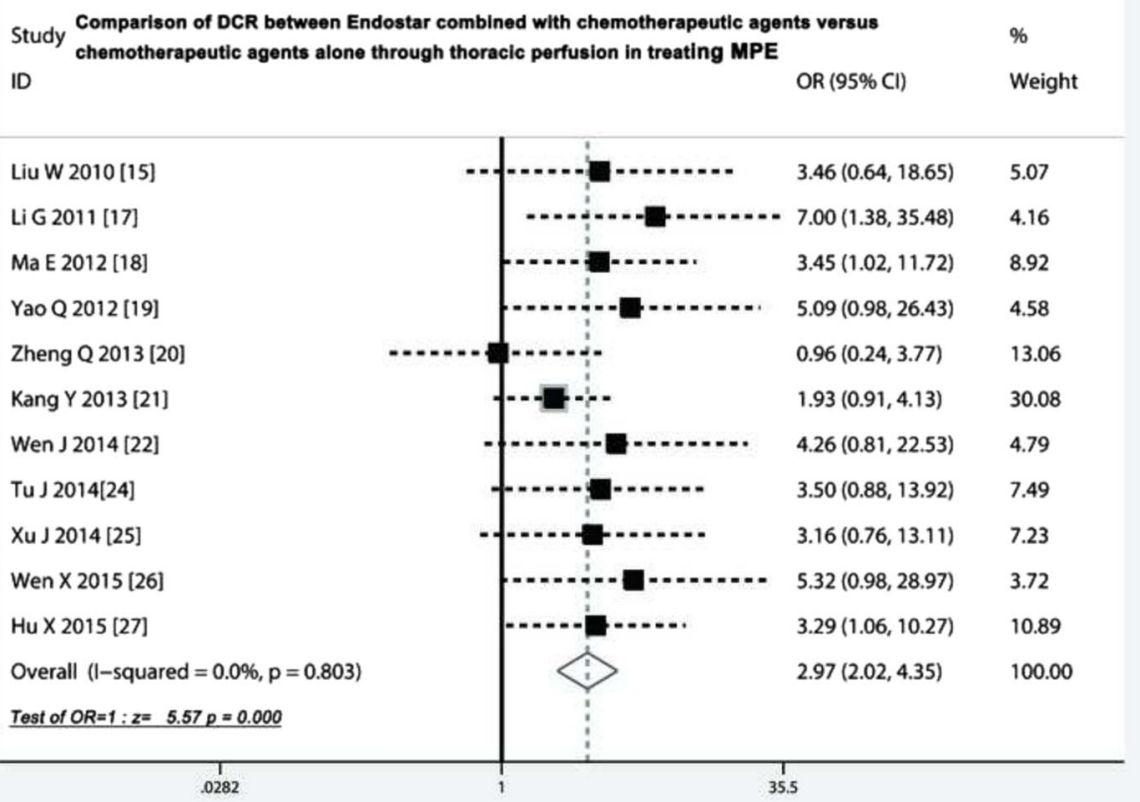

Fig. 3 Comparison of DCR between Endostar combined with chemotherapeutic agents versus chemotherapeutic agents alone through thoracic perfusion for treating MPE. DCR, disease control rate; OR, odds ratio; MPE, malignant pleural effusions 


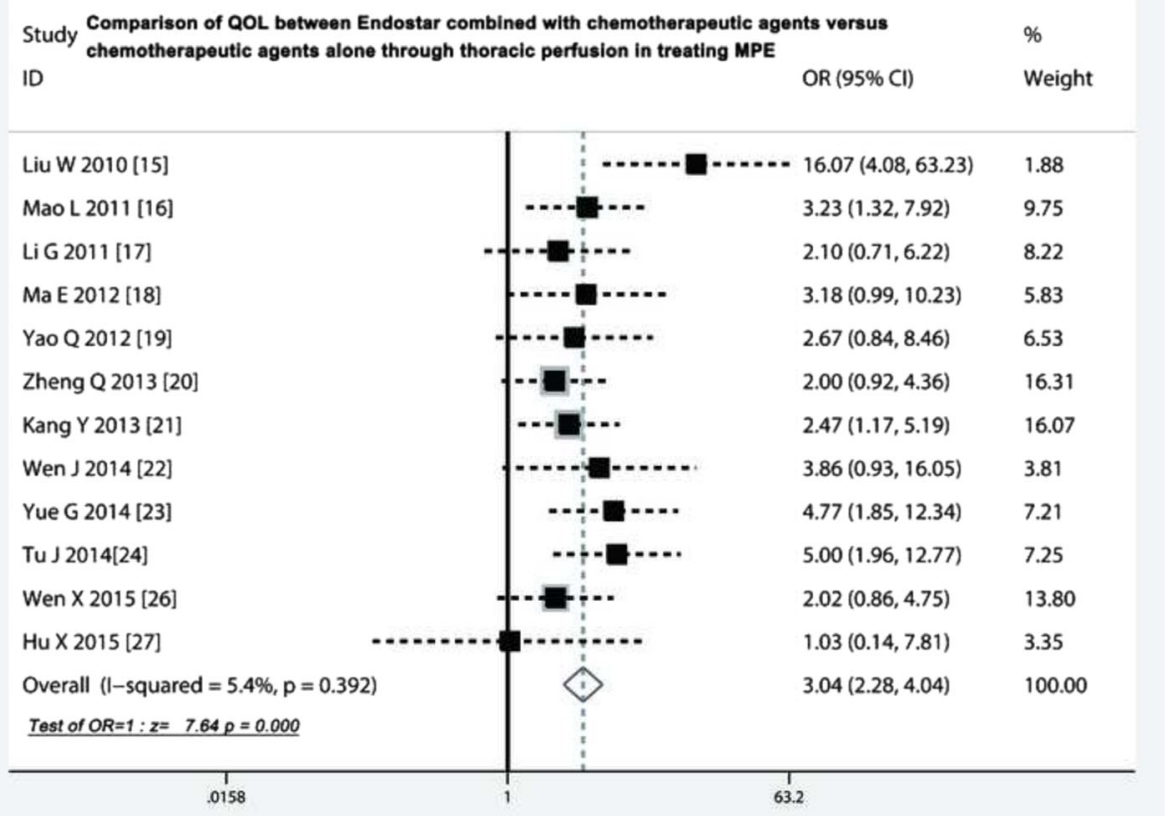

Fig. 4 Comparison of QOL between Endostar combined with chemotherapeutic agents versus chemotherapeutic agents alone through thoracic perfusion for treating MPE. QOL, quality of life; OR, odds ratio; MPE, malignant pleural effusions

suggesting that publication bias did not have an impact on the results (Fig. 7a). The Egger's test showed that $\mathrm{t}$ value was 0.60 with $12^{\circ}$ of freedom $(P=0.562)$ (Fig. $\left.7 \mathrm{~b}\right)$. Get together, all evidence showed that no publication biases existed in these included studies. Test for heterogeneity of meta-regression showed that $\mathrm{Q}$ was 9.548 on $12^{\circ}$ of freedom $(p=0.656)$, and moment-based estimate of between studies variance was zero (tau2 of size of sample $=0$; tau 2 of ITT $=0$ ), which indicated that no obvious variation between groups was observed in this meta-analysis.

\section{Discussion}

In clinical work, malignant pleural effusions (MPE) is a common problem that physicians, oncologists and thoracic surgeons often face. Although many malignant tumors directly lead to accumulation of pleural effusions, the mainly causes for MPE are lung cancer (37.5\%), breast cancer $(16.8 \%)$, and lymphoma (11.5\%). It is reported that 8 to $15 \%$ of lung cancer patients presented symptom of MPE [30]. The local treatment was primarily current mode of administration for patients with MPE, including closed thoracic drainage, chemical

Table 4 Comparison of adverse events between Endostar combined with chemotherapeutic agents versus chemotherapeutic agents alone

\begin{tabular}{|c|c|c|c|c|c|c|c|c|c|c|}
\hline \multirow[t]{2}{*}{ Study } & \multicolumn{2}{|c|}{ Myelotoxicity (\%) } & \multicolumn{2}{|c|}{ Nausea/vomiting (\%) } & \multicolumn{2}{|c|}{ Liver and renal injury (\%) } & \multicolumn{2}{|c|}{ Arrhythmia (\%) } & \multicolumn{2}{|l|}{ Fever (\%) } \\
\hline & Group 1 & Group 2 & Group 1 & Group 2 & Group 1 & Group 2 & Group 1 & Group 2 & Group 1 & Group 2 \\
\hline Li G 2011 [17] & $4(13.3)$ & $4(13.3)$ & $4(13.3)$ & $3(10)$ & - & - & $1(3.3)$ & $0(0)$ & $7(23.3)$ & $6(20)$ \\
\hline Yao Q 2012 [19] & $12(40)$ & $10(30)$ & $5(16.7)$ & $5(16.7)$ & - & - & - & - & - & - \\
\hline Zheng Q 2013 [20] & $17(28.3)$ & $16(26.6)$ & $10(16.7)$ & $5(8.3)$ & - & - & - & - & - & - \\
\hline Kang Y 2013 [21] & $11(24.4)$ & $10(22.2)$ & $15(25)$ & $15(25)$ & $4(8.8)$ & $3(6.6)$ & $2(3.3)$ & $0(0)$ & $7(15.5)$ & $5(11.1)$ \\
\hline Wen J 2014 [22] & $22(73.3)$ & $20(66.6)$ & $6(20)$ & $4(13.3)$ & - & - & $5(16.6)$ & $1(3.3)$ & - & - \\
\hline Yue G 2014 [23] & $10(23.3)$ & $8(18.6)$ & $7(16.3)$ & $6(14)$ & - & - & - & - & - & - \\
\hline Tu J 2014 [24] & $7(15.5)$ & $9(20)$ & $9(20)$ & $9(20)$ & $2(4.4)$ & $2(4.4)$ & $2(4.4)$ & $1(2.2)$ & - & - \\
\hline Xu J 2014 [25] & $14(40)$ & $9(25.7)$ & $4(11.4)$ & $2(5.7)$ & $2(5.7)$ & $1(2.8)$ & $1(2.8)$ & $1(2.8)$ & $1(2.8)$ & $0(0)$ \\
\hline \multirow[t]{2}{*}{ Hu X 2015 [27] } & $7(16.3)$ & $5(12.2)$ & $26(60.4)$ & $20(48.7)$ & $5(11.6)$ & $5(12.1)$ & $3(6.9)$ & $3(7.3)$ & $5(11.6)$ & $5(12.1)$ \\
\hline & \multicolumn{2}{|l|}{$P>0.05$} & \multicolumn{2}{|l|}{$P>0.05$} & \multicolumn{2}{|l|}{$P>0.05$} & \multicolumn{2}{|l|}{$P>0.05$} & \multicolumn{2}{|l|}{$P>0.05$} \\
\hline
\end{tabular}

Values are given as number of patients (\%). Group 1 = Endostar combined with chemotherapeutic agents; Group 2 =chemotherapeutic agents alone 


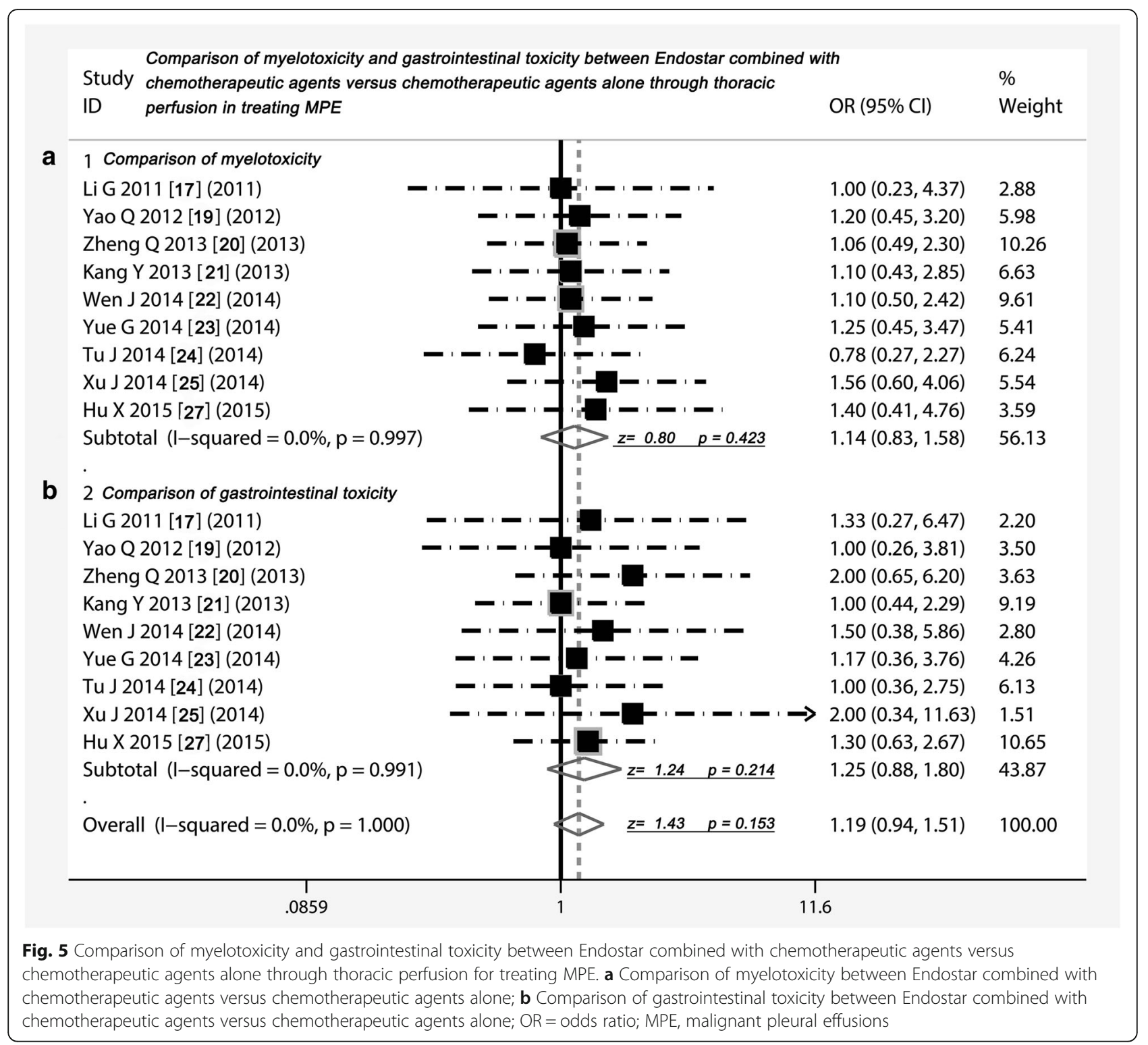

pleurodesis and thoracic perfusion of antineoplastic agents such as doxorubicin, carboplatin, cisplatin, mitomycin $\mathrm{C}$ and 5-fluorouracil [31]. So far, a number of studies have reported on the advantages and security of Endostar combined with chemotherapeutic agents versus chemotherapeutic agents alone through thoracic perfusion for treating MPE. We summed up 13 RCTs and found that Endostar combined with chemotherapeutic agents through thoracic perfusion had better ORR and DCR benefits compared with chemotherapeutic agents alone (odds ratio $=3.58 ; 2.97$ respectively) for treating MPE, translating into a 29 and $18 \%$ absolute improvement respectively. These results corroborate that thoracic perfusion of Endostar take an active role in controlling MPE, which indicate that it is a new potential treatment alternative for treating MPE. Previous studies have demonstrated that Endostar inhibits endothelial cell migration, represses the neovascularization of new tumors, blocks the nutrient supply of tumor cells, and thus suppresses tumor proliferation or metastasis [32]. In addition, Endostar also could inhibit tumor lymphangiogenesis and reduce tumor cells into the bloodstream through the lymphatic [33]. More importantly, Endostar plays an efficient anti-cancer role in MPE through its suppressive effect on angiogenesis and lymphangiogenesis, suggesting that Endostar down-regulated the expression of VEGF-A and VEGF-C, thus inhibit the progression of MPE [34].

MPE is a common manifestation of disease progression to patient with advanced lung cancer and other cancers. In order to control symptoms and improve the quality of life, careful evaluation of pathology and patient treatment 


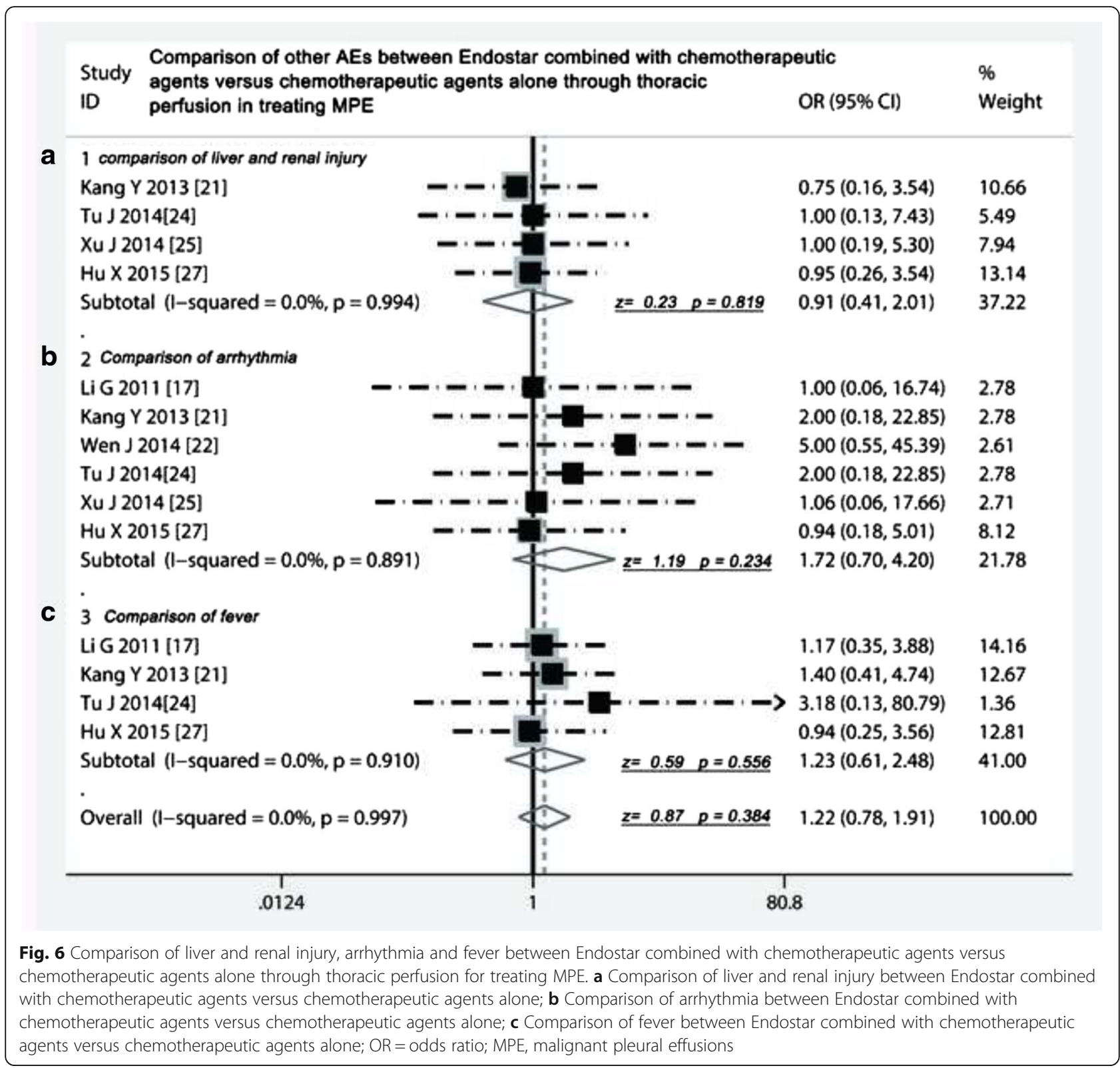

individualization is very crucial [2]. In addition to the cure of the primary disease, the improvement of QOL is important indicator of disease control, especially to malignant tumors. We all known that most of malignant tumor can not be cured, but can slow down the progression and ameliorate symptoms. Our meta-analysis showed that participation of Endostar remarkably improved the QOL of MPE (OR $=3.04,95 \%$ CI 2.28 to 4.04$)$, which led to an absolute $29.1 \%$ improvement of the QOL compared to chemotherapeutic agents alone. Previous study pointed out that Endostar suppress the VEGF-induced tyrosine phosphorylation of KDR/Flk-1 (VEGFR-2) as well as the overall VEGFR-2 expression and the activation of ERK, p38 MAPK, and AKT in human umbilical vein endothelial cells, which shows the relationship between Endostar and VEGF signal pathways and provide a molecular basis for the antiangiogenic effects of Endostar [12]. Also, Endostar can exert its anti-tumor effect via suppressing b-FGFinduced angiogenesis and b-FGF-activated MAPK signaling pathway, suggesting that Endostar might be a useful agent for treatment of malignant tumors [11].

We found that myelotoxicity and digestive reactions are most common adverse reactions, but most of which were grade 1 or 2 and were well tolerated. Through the further analysis, we noticed that the incidence of myelotoxicity, digestive reactions, liver and renal injury, arrhythmia and fever in treatment of Endostar combination was as high as that in chemotherapeutic agents 


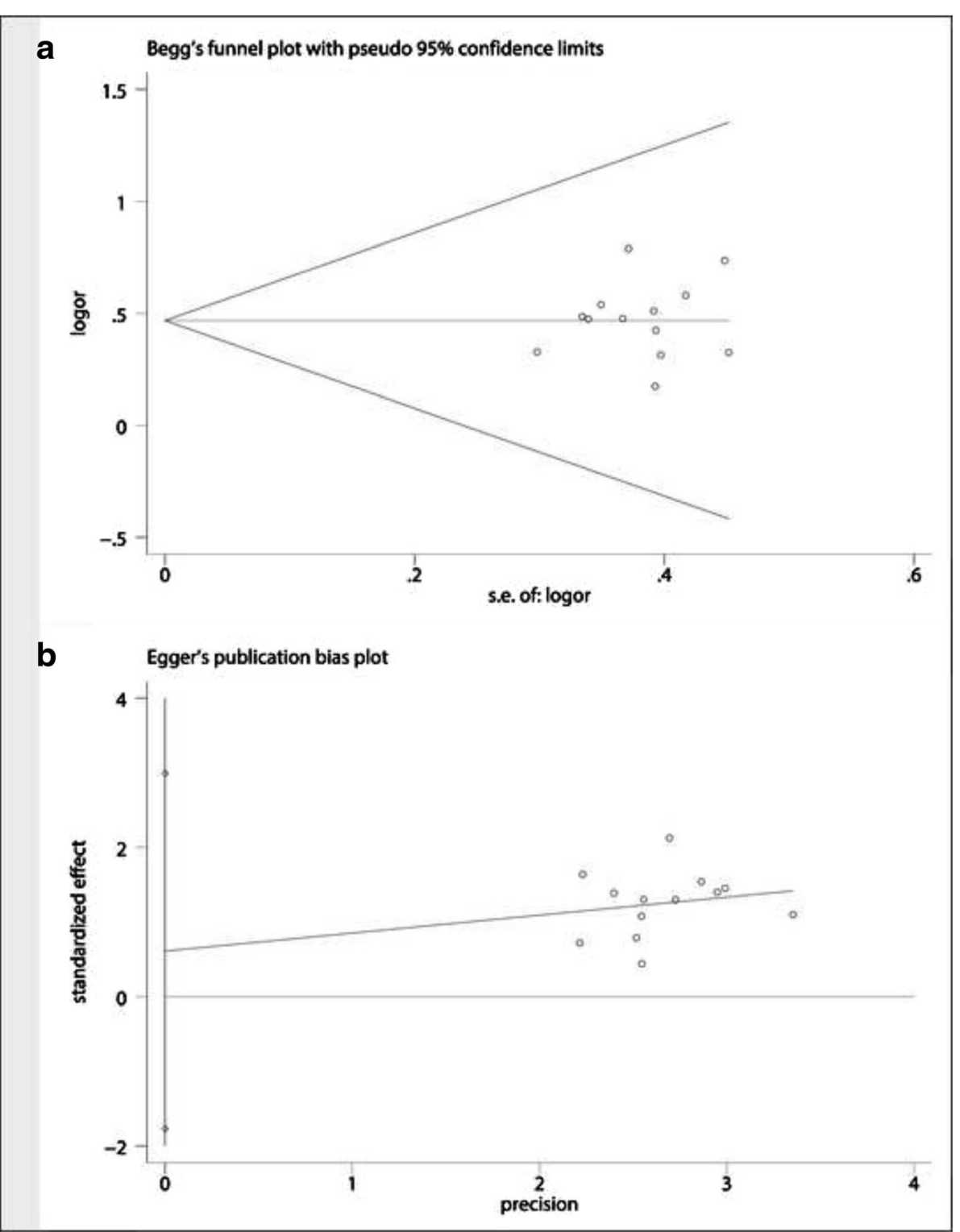

Fig. 7 Assessment of publication bias. a Egger's test did not imply a publication biases; b Begg's test did not show the statistical significance

alone, suggesting that the Endostar did not have an extra impact on the incidence of the AEs. The detection of heterogeneity is very important to meta-analysis, because it will affect the pooled statistical efficacy. We carefully assessed the included studies and found that those studies had a good clinical homogeneity. Moreover, the Egger's test and the Begg's test did not imply the possibility of publication bias.

However, there are some deficiencies in included trials. First, most of studies lack adequate analysis of subgroup data such as age, sex, smoking, histology, and treatment status and so on. Second, design quality of some is relatively low. Third, sample size of some is too small. The last, and mostly importantly, most of patients were from China (because Endostar was approved by the China State Food and Drug Administration and applied in treatment of lung cancer), which may lead to geographical and ethnic differences. In spite of this, these studies still propose a credible suggestion pointing toward that the Endostar is effective and safe for treating MPE, and it is a new choice for treating MPE. Nevertheless, Endostar, as a new molecular targeted drug, still needs to be investigated in the future. Especially, rigorously randomized control trials with large sampler size and multicentered cooperation should be done before it could be recommended in clinic extensively. 


\section{Conclusion}

Thoracic perfusion of Endostar combined with chemotherapeutic agents has a better benefit of ORR and DCR for treating MPE and improves the QOL of MPE patients, compared with chemotherapeutic agents alone. Moreover, the participation of Endostar does not have an extra influence on the incidence of AEs. However, rigorously randomized control trials should be required before it is used widely.

\section{Abbreviations}

AEs: Adverse reactions; AKT: Protein kinase B; Cl: Confidence intervals; CNKI: China National Knowledge Infrastructure; DCR: Disease control rate; ERK: Extracellular regulating kinase; FGF: Fibroblast growth factor; KDR/FIk1: VEGF receptor; MPE: Malignant pleural effusions; OR: Odds ratio; ORR: Overall response rate; p38MAPK: Mitogen activated protein kinases; QOL: Quality of life; RCTs: Randomised controlled trials; SFDA: China State Food and Drug Administration; VEGF: Vascular endothelial growth factor

\section{Acknowledgements}

We appreciate the great help of Mr. Pan Hui, and Miss Gao Jin as interviewers.

\section{Funding}

None.

\section{Availability of data and materials}

The datasets supporting the conclusions of this article are included within the article.

\section{Authors' contributions}

RBX, CXG, LH, GWL and YSY participated in the design and coordination of the study, carried out the critical appraisal of studies, statistical analysis of studies and wrote the manuscript. All authors read and approved the final manuscript.

\section{Competing interests}

The authors declare that they have no competing interests.

\section{Consent for publication}

Not applicable.

\section{Ethics approval and consent to participate}

Ethical approval is not required for this review.

\section{Author details}

${ }^{1}$ Department of Respiratory Medicine, First Affiliated Hospital, Xi'an Medical University, 48 Fenghao West Road, Xi'an 710077, China. ${ }^{2}$ Department of Respiratory Medicine, Gansu Provincial Hospital, Lanzhou, China.

${ }^{3}$ Department of Statistics and Epidemiology, Medical College, Lanzhou University, Lanzhou, China. ${ }^{4}$ Department of Respiratory Medicine, Second Affiliated Hospital, Xi'an Jiaotong University, Xi'an, China.

Received: 20 April 2016 Accepted: 28 October 2016

Published online: 14 November 2016

\section{References}

1. Chen W, Zheng R, Baade PD, Zhang S, Zeng H, Bray F, et al. Cancer statistics in China, 2015. CA Cancer J Clin. 2016;66(2):115-32.

2. Zarogoulidis K, Zarogoulidis P, Darwiche K, Tsakiridis K, Machairiotis N, Kougioumtzi l, et al. Malignant pleural effusion and algorithm management. J Thorac Dis. 2013;5 Suppl 4:S413-9.

3. Jones DR, Taylor MD, Petroni GR, Shu J, Burks SG, Daniel TM, et al. Phase I trial of intrapleural docetaxel administered through an implantable catheter in subjects with a malignant pleural effusion. J Thorac Oncol. 2010;5(1):75-81.

4. Stathopoulos GT, Kalomenidis I. Malignant pleural effusion: tumor-host interactions unleashed. Am J Respir Crit Care Med. 2012;186(6):487-92.
5. Thomas R, Francis R, Davies HE, Lee YC. Interventional therapies for malignant pleural effusions: the present and the future. Respirology. 2014;19(6):809-22

6. O'Reilly MS, Boehm T, Shing Y, Fukai N, Vasios G, Lane WS, et al. Endostatin: an endogenous inhibitor of angiogenesis and tumor growth. Cell. 1997; 88(2):277-85.

7. Sun Y, Wang JW, Liu YY, Yu QT, Zhang YP, Li K, et al. Long-term results of a randomized, double-blind, and placebo-controlled phase III trial: Endostar (rh-endostatin) versus placebo in combination with vinorelbine and cisplatin in advanced non-small cell lung cancer. Thorac Cancer. 2013:4(4):440-8.

8. Rong B, Yang S, Li W, Zhang W, Ming Z. Systematic review and metaanalysis of Endostar (rh-endostatin) combined with chemotherapy versus chemotherapy alone for treating advanced non-small cell lung cancer. World J Surg Oncol. 2012;10:170

9. $\quad$ Song HF, Liu XW, Zhang HN, Zhu BZ, Yuan SJ, Liu SY, et al. Pharmacokinetics of His-tag recombinant human endostatin in Rhesus monkeys. Acta Pharmacol Sin. 2005;26(1):124-8.

10. Wang J, Sun Y, Liu Y, Yu Q, Zhang Y, Li K, et al. Results of randomized, multicenter, double-blind phase III trial of rh-endostatin $(\mathrm{YH}-16)$ in treatment of advanced non-small cell lung cancer patients. Zhongguo fei ai za zhi. 2005;8(4):283-90.

11. Xiao L, Yang S, Hao J, Yuan X, Luo W, Jiang L, et al. Endostar attenuates melanoma tumor growth via its interruption of b-FGF mediated angiogenesis. Cancer Lett. 2015;359(1):148-54.

12. Ling Y, Yang Y, Lu N, You QD, Wang S, Gao Y, et al. Endostar, a novel recombinant human endostatin, exerts antiangiogenic effect via blocking VEGF-induced tyrosine phosphorylation of KDR/Flk-1 of endothelial cells. Biochem Biophys Res Commun. 2007;361(1):79-84.

13. Cao H, Liu J, Lewith GT. Traditional Chinese Medicine for treatment of fibromyalgia: a systematic review of randomized controlled trials. J Altern Complement Med. 2010;16(4):397-409.

14. Cirocchi R, D'Ajello F, Trastulli S, Santoro A, Di Rocco G, Vendettuoli D, et al. Meta-analysis of thyroidectomy with ultrasonic dissector versus conventional clamp and tie. World J Surg Oncol. 2010;8:112.

15. Liu W, Ha M, Ying N, Li J. Efficacy of intrapleural infusion of endostar combined with cisplatin in the treatment of malignant pleural effusion. Shandong Med J. 2010:50(8):79-80.

16. Mao L, Liao G, Wang H, Liu P, Xie G. Observation of clinical efficacy of endostar combined with DDP on malignant bloody pleural effusion. Med J Nat Defend Forces Southwest Chin. 2011;21(7):723-5.

17. Li G, Zhao J-D, Li Y, Di J, Jiang J, Zhao J. Application of endostar combined with bleomycin in the treatment of malignant pleural effusion. Chin J N Drugs. 2011;20(16):1544-7.

18. Ma E, Zou L, Yuan D. Clinical observation on the treatment of malignant pleural effusion with endostar and combined with chemotherapy. Chin Med Pharmcol. 2012;2(15):52-3.

19. Yao Q, Lin Q, Liu S, Shen D, Lin F, Mao W. Efficacy of intrapleural infusion of endostar combined with nedaplatin in the treatment of malignant pleural effusion. J Basic Clin Oncol. 2012;25(6):492-4.

20. Zheng Q. A comparision between intrapleural injection of cisplatin combined with endostar and cisplatin alone in the treatment for malignant pleural effusion. J Chin Oncol. 2013;19(5):386-9.

21. Kang Y, Min J, Fu J, Ma N, Li N, Shan Y, et al. Therapeutic effect of endostar combined with cisdiammi dichloride platinum on malignant pleural effusion. Mod Oncol. 2013;21(11):2485-7.

22. Wen J, Ge W, Li G, Peng Y, Chen G, Wang J. Clinical observation of pleural hyperthermic perfusion chemotherapy with Endostar and Lobaplatin for treatment of malignant pleural effusion. BME \& Clin Med. 2014;18(6):540-3.

23. Yue G, Bai Y, Ma H, Li N, Yang W, Shi L, et al. Analysis of efficacy and security cisplatin endostar in the treatment of non-small cell lung cancer bloody pleural effusion. Mod Diagn Treat. 2014;25(11):2478-80.

24. Tu J, Huang S, Wang M. Clinical efficacy of pleural perfusion with recombinant human endostatin combined with cisdiammi dichloride platinum for advanced non-small cell lung cancer patients with malignant pleural effusion. Pract J Cancer. 2014;29(12):1592-4.

25. Xu J, Qi D, Li X, Wang R. Efficacy of recombinant human endostatin (Endostar) combined with chemotherapy for malignant pleural effusion in non-small cell lung cancer patients. Chin J Clin Oncol. 2014;41(24):1573-6. 
26. Wen X. Clinical observation of recombinant Endostatin combined with the treatment of malignant pleural effusion of non-small cell lung cancer. World Latest Med Info. 2015;15(49):6-7.

27. Hu X, Wang H, Zhang C, Liu P, Wang Y, Li J, et al. Clinical study on intrathoracic chemotherapy with recombinant human endostain combined with cisplatin in treatment of patients with malignant pleural effusion. Clin Med J. 2015;13(3):23-7.

28. Rong B, Zhao C, Gao W, Yang S. Matrine promotes the efficacy and safety of platinum-based doublet chemotherapy for advanced non-small cell lung cancer. Int J Clin Exp Med. 2015;8(9):14701-17.

29. Tan C, Sedrakyan A, Browne J, Swift S, Treasure T. The evidence on the effectiveness of management for malignant pleural effusion: a systematic review. Eur J Cardiothorac Surg. 2006;29(5):829-38.

30. Morgensztern D, Waqar S, Subramanian J, Trinkaus K, Govindan R. Prognostic impact of malignant pleural effusion at presentation in patients with metastatic non-small-cell lung cancer. J Thorac Oncol. 2012;7(10):1485-9.

31. Du N, Li X, Li F, Zhao H, Fan Z, Ma J, et al. Intrapleural combination therapy with bevacizumab and cisplatin for non-small cell lung cancermediated malignant pleural effusion. Oncol Rep. 2013;29(6):2332-40.

32. Huang C, Wang X, Wang J, Lin L, Liu Z, Xu W, et al. Incidence and clinical implication of tumor cavitation in patients with advanced non-small cell lung cancer induced by Endostar, an angiogenesis inhibitor. Thorac Cancer. 2014;5(5):438-46.

33. Shang L, Zhao J, Wang W, Xiao W, Li J, Li X, et al. Inhibitory effect of endostar on lymphangiogenesis in non-small cell lung cancer and its effect on circulating tumor cells. Chin J Lung Cancer. 2014;17(10):722-9.

34. Ma X, Yao Y, Yuan D, Liu H, Wang S, Zhou C, et al. Recombinant human endostatin endostar suppresses angiogenesis and lymphangiogenesis of malignant pleural effusion in mice. PLoS One. 2012;7(12):e53449.

\section{Submit your next manuscript to BioMed Central and we will help you at every step:}

- We accept pre-submission inquiries

- Our selector tool helps you to find the most relevant journal

- We provide round the clock customer support

- Convenient online submission

- Thorough peer review

- Inclusion in PubMed and all major indexing services

- Maximum visibility for your research

Submit your manuscript at www.biomedcentral.com/submit

) Biomed Central 